\title{
Logística reversa e design: uma proposta aplicada a uma empresa de confecção de uniformes profissionais
}

Reverse logistics and design: a proposal applied to a professional uniforms company

MEDEIROS, Dorivalda Santos Neira; doutora; Universidade Federal de Goiás

dorivalda.neira@ufg.br

MARTINS, Bruna Melo; Especialista; Instituto SENAI de Tecnologia Ítalo Bologna

brunamelo-15@hotmail.com

MIRANDA, Jaqueline de Almeida; Especialista; Instituto SENAI de Tecnologia Ítalo Bologna

jackalmeidamiranda@hotmail.com

\section{Resumo}

Aplicando os conceitos de logística reversa pós-consumo, elaborou-se uma proposta com base em design para sustentabilidade que foi desenvolvida e aplicada a empresa de confecção de uniformes profissionais, a empresa Goiás Brasil Uniformes, localizada na cidade de Anápolis-GO. O objeto de estudo, deste trabalho, foi gestão do fim da vida útil dos uniformes que a empresa confecciona para os profissionais da limpeza urbana da cidade de Anápolis. Os uniformes após sua vida útil foram coletados, selecionados e serviram de material para a confecção de novos produtos. Para tanto, realizou-se um estudo acerca das possibilidades de reutilização (material têxtil e aviamentos) e a análise da viabilidade econômica da proposta para a empresa.

Palavras Chave: resíduo; têxtil; reutilização e logística reversa.

\begin{abstract}
Applying the concepts of post-consumer reverse logistics, a proposal based on design for sustainability was developed and applied to the professional uniforms manufacturing company, Goiás Brasil Uniformes, located in the city of Anápolis-GO. The objective of this study was the management of the end of life of the uniforms that the company makes for the urban cleaning professionals of the city of Anápolis. The uniforms after their useful life were collected, selected and used as material for the making of new products. For this, a study was carried out on the possibilities of reuse (textile material and supplies) and the economic feasibility analysis of the proposal for the company.
\end{abstract}

Keywords: residues; textiles; reuse and logistics reverse. 


\title{
1 Introdução
}

Ao longo do ciclo de produção e vida útil de uma peça de vestuário são gerados diversos resíduos sólidos. Além das próprias peças de roupa que em algum momento serão descartadas, incluem-se aqui também as embalagens não reutilizáveis ou não recicláveis. Os efeitos causados pelo descarte dos resíduos sólidos ao bem-estar ambiental e social do planeta já são evidentes, alerta SALCEDO (2014).

Entre os desafios para a indústria têxtil, apontados por SALCEDO (2014), no quesito geração e gestão dos resíduos está:

\begin{abstract}
Minimizar os resíduos nas operações de produção, junto aos fornecedores e ao fim da vida útil dos produtos têxteis; desenvolver um uso eficaz dos resíduos têxteis, promovendo segunda vida aos materiais e; aumentar a vida útil dos produtos e gerar uma economia circular, em que os resíduos sejam empregados novamente como materiais de valor agregado. (SALCEDO,2014, p.28)
\end{abstract}

Portanto, qualquer iniciativa, cujo objetivo seja minimizar impactos ambientais, pode ser entendida como um modelo de negócio mais sustentável. Nesse sentido, a sustentabilidade representa uma oportunidade para criar novos modelos de negócio.

Abordar os impactos ambientais e sociais da atividade de uma empresa implica analisar os elementos fundamentais de seu modelo de negócios. Tal necessidade proporciona à empresa uma excelente oportunidade de desenvolver práticas inovadoras relacionadas ao design, à produção e à comercialização de seus produtos. $O$ design para sustentabilidade reflete estratégias aplicáveis ao longo do ciclo de vida do produto (SALCEDO, 2014).

O design para sustentabilidade não é impulsionado somente por designers e empresas, mas também pelo consumidor, que tem um papel fundamental na hora de reverter os impactos negativos dos produtos têxteis. Para GWILT e RISSANEM (2011) apud SALCEDO (2014) o designer/estilista tem de ver a estratégia de sustentabilidade como uma oportunidade de inovação.

O objetivo desta proposta é aplicar as teorias do design para sustentabilidade através do reaproveitamento dos tecidos/aviamentos de uniformes profissionais após a vida útil. Ao retornar para o processo produtivo da empresa fornecedora, os uniformes serviram de material para o desenvolvimento de novos produtos.

\section{Fundamentação teórica}

Em apoio ao design para sustentabilidade, a Lei no 12.305 de 2 de agosto de 2010 e seu regulamento, Decreto № 7.404 de 23 de dezembro de 2010 tratam da Política Nacional de Resíduos Sólidos (PNRS) onde são destacadas a responsabilidade compartilhada pelo ciclo de vida dos produtos e a logística reversa. Nos termos da PNRS, a responsabilidade compartilhada pelo ciclo de vida dos produtos é:

\footnotetext{
"o conjunto de atribuições individualizadas e encadeadas dos fabricantes, importadores, distribuidores e comerciantes, dos consumidores e dos titulares dos serviços públicos de limpeza urbana e de manejo dos resíduos sólidos, para minimizar o volume de resíduos sólidos e rejeitos gerados, bem como para reduzir os impactos causados à saúde humana e à qualidade ambiental decorrentes do ciclo de vida dos produtos, nos termos desta Lei".
} 
(http://www.mma.gov.br)

A logística reversa é um dos instrumentos para aplicação da responsabilidade compartilhada pelo ciclo de vida dos produtos. A PNRS define a logística reversa como um

\footnotetext{
"instrumento de desenvolvimento econômico e social caracterizado por um conjunto de ações, procedimentos e meios destinados a viabilizar a coleta e a restituição dos resíduos sólidos ao setor empresarial, para reaproveitamento, em seu ciclo ou em outros ciclos produtivos, ou outra destinação final ambientalmente adequada." (http://www.mma.gov.br)
}

A partir de agosto de 2010, baseado no conceito de responsabilidade compartilhada, a sociedade como um todo - cidadãos, governos, setor privado e sociedade civil organizada passou a ser responsável pela gestão ambientalmente adequada dos resíduos sólidos.

Aplicando a estratégia de design para a sustentabilidade e a logística reversa (instrumento para aplicação da responsabilidade compartilhada pelo ciclo de vida dos produtos) pretende-se minimizar o impacto ambiental provocado pelo descarte inadequado dos resíduos sólidos têxteis. Portanto, realizou-se um estudo de caso em uma empresa de confecção, a Goiás Brasil Uniformes, fabricante de uniformes profissionais e os resíduos descartados por um de seus clientes.

\section{Procedimentos metodológicos}

A empresa de confecção está situada na cidade de Anápolis-GO e o cliente é a empresa responsável pela limpeza urbana da mesma cidade. Os materiais, objeto deste estudo, foram os resíduos sólidos têxteis após o ciclo de vida útil, ou seja, as peças/uniformes que foram descartadas após o uso pelos profissionais da limpeza urbana. Em geral, os materiais têxteis utilizados em uniformes profissionais têm durabilidade, e muitas vezes, estes são descartados ainda com valor agregado, no que tange ao potencial de utilização dos mesmos.

Nesta proposta, os conceitos de logística reversa e sustentabilidade foram aplicados na prática através do reaproveitamento dos tecidos/aviamentos dos uniformes após a vida útil, ou seja, após o uso pelos profissionais da limpeza urbana. Ao retornar para o processo produtivo da empresa fornecedora, os uniformes serviram de material para o desenvolvimento de novos produtos.

Os produtos desenvolvidos foram revertidos para a empresa de limpeza urbana, na forma de brindes, para os funcionários e também, para serem distribuídos à população da cidade na forma de brindes, neste caso, pela empresa de confecção. Além de explorar o potencial de reutilização do material têxtil e retorno do mesmo ao processo produtivo da confecção, propôs-se uma parceria entre as duas empresas (confecção e limpeza urbana) na promoção da educação socioambiental e responsabilidade compartilhada, nos termos da Lei 13 . 305, que trata da gestão dos resíduos sólidos.

\subsection{Diagnóstico}

A empresa Goiás Brasil Uniformes fica situada na cidade de Anápolis, está no mercado há 9 anos e sempre atuou na área de confecção de uniformes profissionais. Seus clientes são empresas do ramo de alimentação, setor automobilístico, segurança, limpeza urbana, entre outras. A empresa possui 35 (trinta e cinco) colaboradores em sua linha de produção, que é dividida em 3 (três) setores: preparação, costura e acabamento. 
O setor de preparação é composto pelo setor de modelagem, corte, bordado, serigrafia, costura de bolsos e separação de aviamentos. O setor de costura é responsável pelo fechamento das peças, a costura. No setor de acabamento realizam-se a finalização e revisão das peças (caseado, travetagem, pregar botão, retirada de linhas, controle de qualidade, passadoria e embalagem). Atualmente, a empresa possui uma capacidade produtiva interna de 10.000 peças/mês.

Em primeiro momento, foi feita uma análise dos clientes atendidos pela empresa Goiás Brasil Uniformes, após essa análise, optou-se por questões de logística, de técnica e de público alvo fazer um estudo somente com os uniformes fabricados pela empresa para os profissionais da limpeza urbana (uniformes dos garis). Esta opção foi viabilizada porque a empresa responsável pela limpeza urbana recolhe os uniformes usados para realizar a troca por um novo.

Após uma visita à empresa responsável pela limpeza urbana e análise das peças recolhidas pela mesma foram observadas algumas possibilidades de reutilização dos materiais têxteis e aviamentos. Na Figura 1, observam-se os uniformes que são usados pelos profissionais da limpeza urbana: uma camiseta manga longa em malha PV - Caiman (67\% poliéster e $33 \%$ viscose) e calça em Cedrobrim Super 100\% algodão. Os aviamentos utilizados são: linhas, faixa refletiva, elástico e torçal (para calça).

Figura 1 - Uniforme dos profissionais de limpeza urbana da cidade de Anapólis-GO.

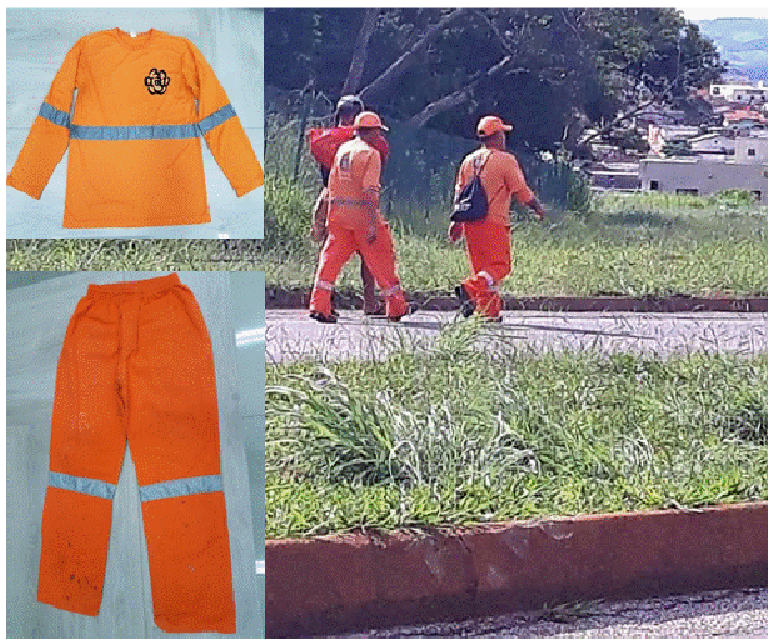

Fonte: Autores (2018)

O problema identificado, neste estudo de caso, foi o descarte dos uniformes e os motivos pelos quais eram descartados. Há dois motivos informados para a troca por um uniforme novo: desgaste e demissão. Na maioria dos casos, por desgaste e, em alguns casos, por motivos de demissão do funcionário que tem que devolver a peça. Em ambos os casos, os uniformes são recolhidos pela empresa responsável pela limpeza urbana e destinados ao aterro sanitário da cidade, onde são enterrados juntamente com outros materiais (luvas, botas, sacos plásticos, entre outros) utilizados pelos funcionários da limpeza.

O descarte inadequado e o potencial de reutilização do material têxtil foi o que nos instigou a buscar possibilidades de retorno dos materiais ao processo produtivo da empresa Goiás Brasil Uniformes. Na Figura 2, pode-se observar o comparativo entre peças novas e peças após o 
uso, recolhidas pela empresa de limpeza urbana.

Figura 2 - Comparativo entre peças novas e peças após o uso.

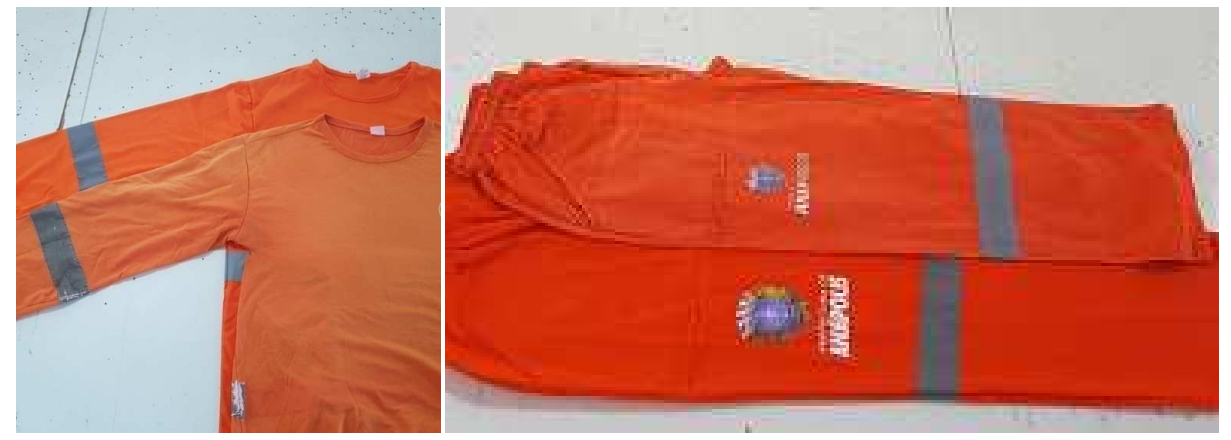

Fonte: Autores (2018)

Observou-se que o material têxtil apresentava desbotamento (Figura 2) e em alguns casos, muitas manchas no lado direito da peça. Uma observação interessante, relativa ao desbotamento, é que o lado avesso fica bem preservado, ou seja, permanece a cor viva, o que nos possibilitou usar o lado avesso do tecido em alguns produtos. Em outras palavras, a solidez da cor é preservada no lado avesso das peças.

Após recolher as peças, foi realizado um estudo sobre as possibilidades de reutilização do material têxtil e aviamentos. Vale salientar que para viabilização deste projeto as peças recolhidas tiveram que passar por um processo de lavanderia antes da reutilização, por serem materiais têxteis que entram em contato com o lixo urbano. Este projeto foi composto de processos de criação, produção dos protótipos e gestão de custos.

\section{Resultados da Pesquisa e Discussão}

Os produtos desenvolvidos foram: lixeira de tecido para automóveis, mochila tipo saco e sacola, produzidos a partir do reaproveitamento dos materiais. A mochila tipo saco e a sacola foram propostas de brinde para os funcionários da limpeza, que foram identificados utilizando este tipo de produto (ver Figura 1).

Na Figura 3, pode-se observar a sacola desenvolvida com a parte superior da calça, aproveitando os bolsos, frontal e traseiro, como compartimentos. No design deste produto a alça utilizada foi o cós da calça.

O produto desenvolvido e apresentado na Figura 3, também serve para ser utilizado como sacola retornável. O design, a composição e a gramatura dos materiais utilizados (Cedrobrim Super $100 \%$ algodão) permitem que o produto seja utilizado como sacola retornável ou ecobag. 
Figura 3 - Desenho técnico da sacola e produto acabado.

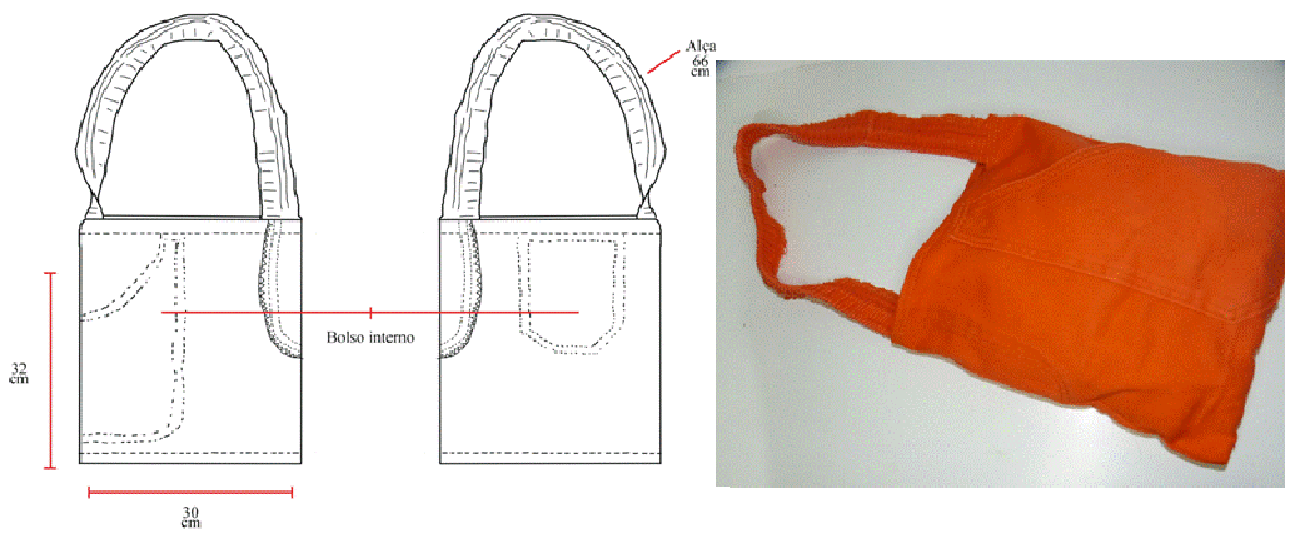

Fonte: Autores (2018)

A inspiração para o design da mochila tipo saco, foi a partir de uma fotografia dos funcionários no final do turno de trabalho (ver figura 1), os quais foram vistos portando esse tipo de produto. Para tanto, a mochila tipo saco foi desenvolvida pela reutilização das pernas da calça, como podemos observar na Figura 4. O torçal utilizado, neste produto, é o torçal utilizado no cós das calças, que também foi reaproveitado.

Figura 4 - Desenho técnico da mochila tipo saco e mochila acabada.
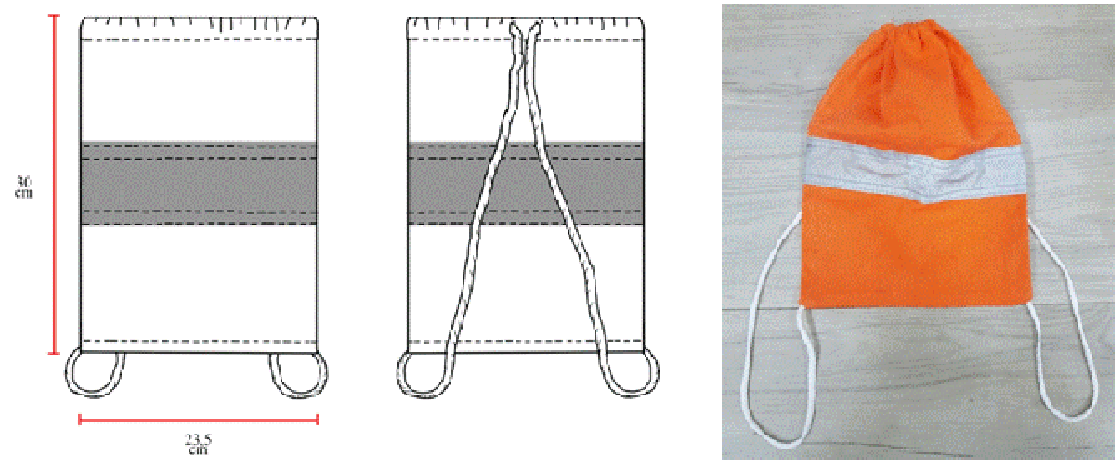

Fonte: Autores (2018)

Os produtos mochila tipo saco e sacola retornável foram desenvolvidos com objetivo de serem brindes para os funcionários da limpeza que será distribuído por parte da empresa de limpeza urbana em datas festivas, por exemplo, fim de ano.

O produto lixeira de tecido para automóveis foi desenvolvido para promover uma ação educativa e de promoção das duas empresas, a empresa responsável pela coleta de lixo urbano e a empresa Goiás Brasil Uniformes, realizando uma ação de conscientização sobre o descarte do lixo. Para isso, o objetivo foi o de promover uma ação educativa com a distribuição das lixeiras de tecido para a população, pelos próprios funcionários da limpeza e produzidas com o material reutilizado do próprio uniforme que eles usam. Essa ação será realizada durante o desfile 
comemorativo pelo aniversário da cidade de Anápolis, onde os profissionais da limpeza urbana participam do desfile.

A empresa de confecção aplicará sua logomarca em alguns produtos, como pode ser visto no detalhe da Figura 5. A lixeira para automóveis foi confeccionada com o lado avesso do tecido, cuja cor estava mais preservada. Este produto também foi produzido com o material têxtil da camiseta de manga longa, ou seja, em malha.

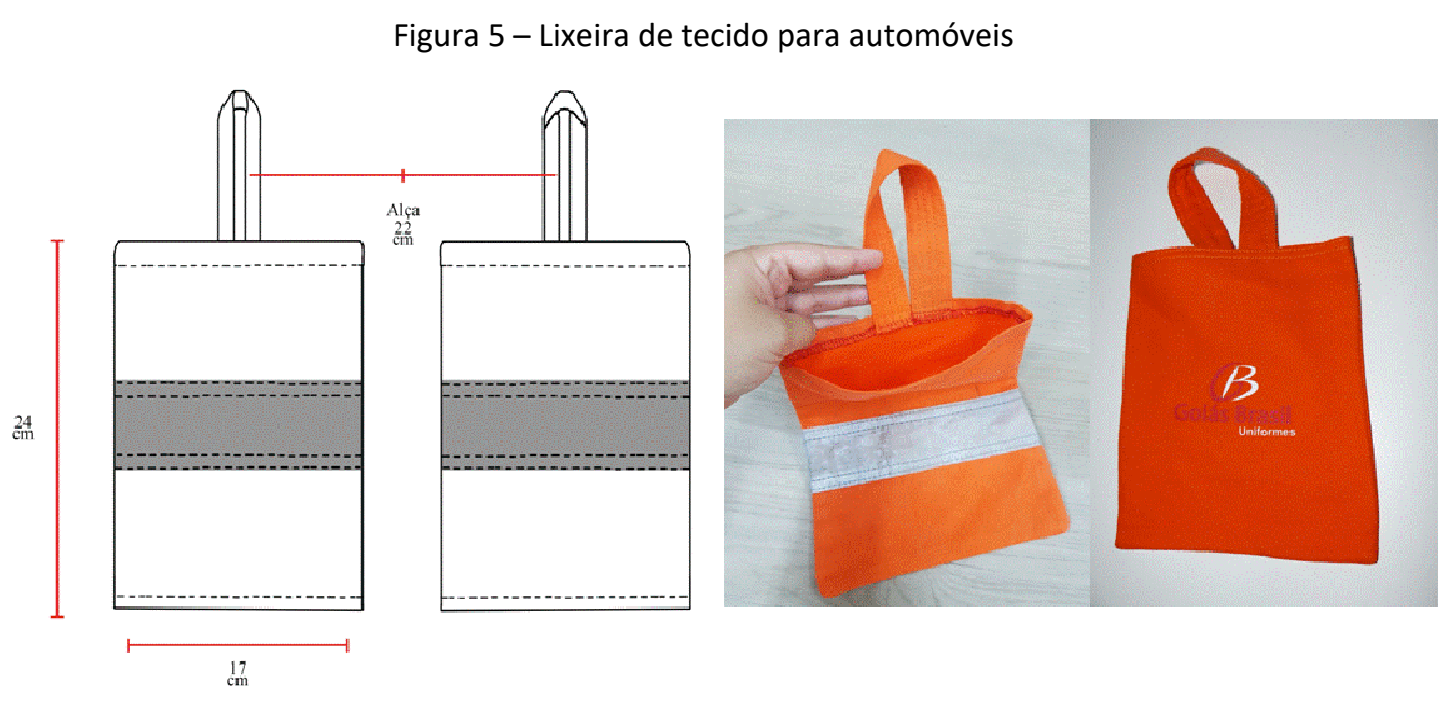

Fonte: Autores (2018)

\subsection{Análise de custo para viabilidade da proposta}

Numa análise de custo/benefício para a empresa de confecção Goiás Brasil Uniformes pode-se observar no Quadro 1 que em média o custo de cada peça para empresa sairia em torno de $R \$ 1,94$ (um real e noventa e quatro centavos). Nesta análise, foi considerada a política da própria empresa na formação do seu preço de venda.

Quadro 1 - Análise de custos para a empresa de confecção.

\begin{tabular}{lllll}
\hline PRODUTO & \multicolumn{3}{c}{ CUSTOS } \\
\cline { 2 - 5 } & FIXO EMPRESA/PEÇA & PRODUTO/PEÇA & LAVANDERIA/PEÇA & FINAL \\
\hline Sacola & $\mathrm{R} \$ 1,14$ & $\mathrm{R} \$ 0,30$ & $\mathrm{R} \$ 0,50$ & $\mathrm{R} \$ 1,94$ \\
\hline Mochila saco & $\mathrm{R} \$ 1,14$ & $\mathrm{R} \$ 0,30$ & $\mathrm{R} \$ 0,50$ & $\mathrm{R} \$ 1,94$ \\
\hline Lixeira carro & $\mathrm{R} \$ 1,14$ & $\mathrm{R} \$ 0,30$ & $\mathrm{R} \$ 0,50$ & $\mathrm{R} \$ 1,94$ \\
\hline
\end{tabular}

Fonte: Autores (2018)

A empresa estima produzir 1000 (mil) lixeiras de tecido ( ver Figura 5) para promover a ação educativa durante o aniversário da cidade, portanto precisará recolher da empresa de limpeza urbana para reutilização 60 (sessenta) camisetas de manga longa em malha, 260 (duzentos e sessenta) calças usadas e para esse produto fará um investimento de $\mathrm{R} \$ \mathbf{1 9 4 0 , 0 0}$ (mil novecentos e quarenta reais).

Para confecção de 100 (cem) sacolas retonáveis (ver Figura 3) e 200 (duzentas) mochilas 
tipo saco (ver Figura 4), a empresa de confecção fará um investimento de $\mathrm{R} \$ 582,00$ (quinhentos e oitenta e dois reais) e os materiais reutilizados, neste caso, seriam as sobras de tecido das 260 calças utilizadas na confecção das lixeiras de tecido. As sacolas e as mochilas seriam brindes que seriam doados aos funcionários da limpeza.

\section{Considerações finais}

Para viabilizar a produção das 1300 (mil e trezentas) peças (lixeira, sacola e mochila tipo saco) a coleta de material, após o uso, seria feita durante 3 (três) meses, pois a média de descarte (troca/substituição) é de 60 (sessenta) conjuntos por mês.

Para o departamento financeiro da empresa Goiás Brasil Uniformes, o investimento de R\$ 2.566,00 (dois mil quinhentos e sessenta e seis reais) uma vez ao ano, seria viável para empresa. Além da viabilidade econômica, a empresa está aplicando sua responsabilidade compartilhada na gestão dos resíduos sólidos e os incontestáveis benefícios ao ambiente. Com a logomarca da empresa nas lixeiras, a empresa também se promove ao divulgar sua marca, além de promover a ação social e educativa, ao distribuir as lixeiras para a população e as mochilas e sacolas, para os funcionários da limpeza urbana.

A reutilização de resíduo sólido têxtil por parte da Goiás Brasil Uniformes faz com esta seja uma empresa que pratica a Política Nacional de Resíduos Sólidos (PNRS) instituídos desde 2010, onde a logística reversa é um dos instrumentos para aplicação da responsabilidade compartilhada pelo ciclo de vida dos produtos, neste estudo, a gestão do fim da vida útil.

\section{Referências}

BRAUNGART, M. e MCDONOUGH, W. Cradle to cradle: Criar e reciclar ilimitadamente. São Paulo: Editora G Gili, $1^{\circ}$ Ed., 2013.

FLETCHER, K. e GROSE, L. Moda e Sustentabilidade: Design para a mudança. São Paulo: Editora Senac São Paulo, 2011.

GWILT, A.; RISSANEN, T.Shaping sustainable fashion. Erthscan, 2011.

LAWSON, B. How designers think: the design process desmystified. Oxford, Archquitectural Press, $4^{\circ}$ Ed., 2006.

LIGER, I. Moda em 360 graus: design, matéria-prima e produção para o mercado global. São Paulo: Editora Senac, 2012.

MINISTÉRIO DO MEIO AMBIENTE. Política Nacional de Resíduos Sólidos (PNRS). In: Ministério do Meio Ambiente, $2018 \quad$ (http://www.mma.gov.br/cidades-sustentaveis/residuosperigosos/logistica-reversa).

REFOSCO, E.; MAZZOTTI, K.; SOTORIVA, M.; BROEGA, A. C. O novo consumidor de moda e a sustentabilidade. Anais do VII Colóquio de Moda - 12 a 14 de setembro de 2011.

SALCEDO, H. Moda ética para um futuro sustentável. Barcelona: Editora Gustavo Gili, 2014.

TREPTOW, D. Inventando Moda: planejamento de coleção. São Paulo: Edição da Autora, $5^{\circ}$ Ed., 2013. 